\title{
Pneumonia in Slaughtered Sheep in Libya: Gross and Histopathological Findings
}

\author{
Zahra MA. Mohammed, Wafa M. Ibrahim, and Intisar O. Abdalla
}

\section{ABSTRACT}

This study was conducted to determine the prevalence of pneumonia in sheep in municipality of El-Beida, Libya. To achieve the goal, samples were collected from October 2020 to April 2021. The lungs of 525 sheep carcasses were subjected to gross examination and those suspected to be infected with pneumonia were studied at histopathological level. Pneumonia was detected in $141(26.9 \%)$ carcasses. Based on histopathological lesions $\mathbf{4 0 . 4 \%}$ with interstitial pneumonia $37.6 \%$ with fibrinous bronchopneumonia, $14.2 \%$ were affected with suppurative bronchopneumonia, $3.5 \%$ with haemorrhagic pneumonia, $2.1 \%$ were affected with pleuritis and $1.4 \%$ with embolic pneumonia. In addition $0.7 \%$ of the lungs showed aspiration pneumonia. The most common form of pneumonia was interstitial pneumonia and the gross and histological lesions of the different forms of pneumonia were consistent with the findings of other studies. In conclusion, the results of this study indicates that the prevalence of pneumonia in slaughtered sheep is relatively high and seems to be the most important condition in sheep in Libya. Further studies are recommended to identify the etiological agents of pneumonia in sheep.

Keywords: Histopathology, Libya, pneumonia, sheep.
Published: February 10, 2022

ISSN: 2736-6596

DOI : 10.24018 / ejvetmed.2022.2.1.18

\section{Z. MA. Mohammed*}

Department of Basic Veterinary Medicine Sciences, Faculty of Veterinary Medicine, Omar Al-Mukhtar University El-Beida, Libya.

(e-mail: zahra.mohhammed@omu.edu.ly) W. M. Ibrahim

Department of Basic Veterinary Medicine Sciences, Faculty of Veterinary Medicine, Omar Al-Mukhtar University El-Beida, Libya.

I. O. Abdalla

Department of Basic Veterinary Medicine Sciences, Faculty of Veterinary medicine, Omar Al-Mukhtar University El-Beida, Libya.

*Corresponding Author

\section{INTRODUCTION}

Livestock has an important role in the subsistence and in economic growth in Africa [1]. The livestock sector in Libya is an important sector, as the animal population is estimated at about 5,000 heads of cattle, 6,500,000 heads of small ruminants, 110,000 slippers of camels, in addition to 12,000 of the equine species and 15 million chicken birds [2].

However, the performance of the livestock sector remains negatively affected by the spread of animal diseases of economic importance, which may be endemic to the country, and in Libya there is no accurate information about animal diseases epidemiological status, especially with regard to the degree of their danger, extent, spread, importance and distribution. It should be noted that the possibility of eradicating the disease by knowing the time, places and nature of its spread and by taking the appropriate measures to contain it and eliminate it gradually [3].

Sheep are one of the main sources of red meat in Libya so are the most commonly slaughtered animals for human consumption. The pastures of Aljabal Alakhder (Green Mountain) in the east part of Libya are an important part of the national economy for sheep production. However, there is not enough information about the types and the nature of the diseases that affect sheep in Libya in general and the municipality of Aljabal Alakhder in particular. Since this region is mountainous, it is expected that the most prevalent diseases are respiratory diseases.
Respiratory diseases are the most serious sheep problem in all major sheep-producing countries and are mainly the result of a complex combination of infectious agents (bacteria, mycoplasma, viruses, fungi, and parasites), host defense, environmental variables, and stress [3]. Furthermore, age, geographic location, nutrition, unsanitary circumstances, abrupt feed changes, and a low level of herd health status are aspects to consider as risk factors for respiratory diseases. Besides mortality respiratory diseases cause reduced growth rate, carcass condemnation and consequent substantial economic impact on animal husbandry because of the need to activate chemotherapeutic and immunization programs [4]. In order to understand and design a better control strategy, there is still a need for identifying the types and nature of lung lesions then the causes of respiratory diseases of sheep in each region. The main respiratory disease, pneumonia, is caused by inflammation of the lung tissues and is found in sheep all over the world. It is regarded one of the leading causes of death in the small ruminant industry [5], [6].

Since most types of pneumonia are chronic or subclinical infection, the open breeding system of sheep and poor veterinary services in most parts of Libya, the clinical diagnosis of pneumonia is difficult. Therefore, apart from its primary role, a slaughterhouse can also be utilized as an easy and cheap source of data for evaluation of the epidemiological aspects of animal diseases including pneumonia [7]-[9]. 
Respiratory diseases including, pneumonia have been studied in the sheep in the field and slaughter houses in some countries [7]-[12]. In Libya there is a lack of information about the incidences of respiratory diseases in sheep in general and pneumonia in particular. To our knowledge, only one a retrospective study in the western part of Libya, specifically Tripoli, showed that fibrous pneumonia is one of the most common lung diseases, as it included more than $60 \%$ of the total cases diagnosed in the pathology department during the specified period (1987-1996) [13]. However, to date there have been no study that has directly identify the incidence, types and the nature of pneumonia in Libya.

Therefore, this study was conducted to determine a first estimate of the prevalence of pneumonia in sheep, by identifying the common pathological gross and histopathological lung lesions of slaughtered sheep in Libya in order to give baseline data for future monitoring.

\section{ANIMAL AND METHODS}

\section{A. Study Area}

The study was carried out in some El-Beida (the big city in Aljabal Alakhder) slaughterhouses, in Eastern province of Libya, from October 2020 to April 2021 during the wet and dry seasons. The sheep come to these slaughterhouses from municipality of El-Beida which including El-Beida and the surrounding areas. Municipality of El-Beida is located between latitude $32^{\circ} 45^{\prime} \mathrm{N}$ and longitude $21^{\circ} 44^{\prime} \mathrm{E}$ with altitude $623 \mathrm{~m}$ above sea level. This area has a mild mediterranean climate and the annual rainfall is $400 \mathrm{~mm}$. The average temperature in the hottest months is above $22^{\circ} \mathrm{C}$. The municipality of El-Beida is bordered on the south by a dry semi-desert area, while on the north it is bordered by the Mediterranean Sea. Due to this weather, the sheep feed on grass from April to mid-May, and on the remnants of the harvest of wheat and barley fields from mid-May to the end of June. As for the rest of the year, their food depends on imported fodder, especially barley. An average population of 408782 sheep live in this province [14].

\section{B. Study Animals}

The animal population involved in this study was all sheep which were slaughtered in some El-Beida slaughter houses. The slaughtered sheep were local breeds, mostly male animals, their age more than 4 months and all the animals were submitted for routine slaughter. All sheep are managed under a pastoral production system. Sheep are usually mixed with other types of livestock (goats, cows, dogs and camels in some areas).

\section{Sample Collection}

In this study, lungs from 525 native sheep underwent gross examination for the presence of pneumonic lesions. Then lungs with pneumonic lesions (organs showing parasitic lesions were excluded) were selected purposively, were photographed and were taken for pathologic investigations. Representative pieces of tissues (4-5 mm in thickness) were then taken from the pneumonic lungs, fixed with $10 \%$ neutral buffered formalin, and transported to Omar El-Mukhtar University, Veterinary Pathology Laboratory.

\section{Pathological Investigation}

Tissue samples $1 \mathrm{~cm}^{3}$ in thickness were then dehydrated in graded ethanol and embedded in paraffin. Sections $5 \mu \mathrm{m}$ in thickness using rotary microtome (Leica, Germany), then were stained with Harri's haematoxylin and eosin [15], [16] and examined by an ordinary light microscope. Finally the stained slides were examined systematically at $10 \mathrm{X}$ and $100 \mathrm{X}$ magnifications for the presence of characteristic and/or suggestive lesions using ordinary light microscope. The different forms of pneumonia were then classified according to the involvement of pulmonary regions and anatomical sites and nature of the inflammatory exudate and reaction present [17], [18].

\section{RESUlts}

\section{A. Pathological Findings of Pneumonia}

Pneumonia was detected in 141 (26.9\%) carcasses. Prevalence rate of the types of pneumonia was determined and was classified according to macroscopic appearance (texture, exudation, distribution and sites of lesions) and confirmed by microscopic findings. Rendering to these findings, 7 different types of pneumonia were observed which were interstitial pneumonia, fibrinous bronchopneumonia, suppurative bronchopneumonia, haemorrhagic pneumonia, pleurisy, embolic pneumonia and aspiration pneumonia (Table I). The prevalence of pneumonia is shown in table one, the highest number of examined samples had interstitial pneumonia.

TABLE I: PREVALENCE OF PNEUMONIA TYPES FOUND IN SHEEP BY HISTOPATHOLOGICAL DIAGNOSIS IN SLAUGHTERED SHEEP IN LIBYA, BETWEEN 2020 AND 2021

\begin{tabular}{cccc}
\hline \hline Lesions & $\begin{array}{c}\text { No of } \\
\text { affected } \\
\text { lungs }\end{array}$ & $\begin{array}{c}\text { No of affected/ } \\
\text { total affected } \\
(\%)(\mathrm{n}=141)\end{array}$ & $\begin{array}{c}\text { No of affected/ } \\
\text { total examined } \\
\text { sheep (\%) } \\
(\mathrm{n}=525)\end{array}$ \\
\hline \hline $\begin{array}{c}\text { Interstitial pneumonia } \\
\text { Fibrinous }\end{array}$ & 57 & $40.4 \%$ & $10.9 \%$ \\
bronchopneumonia & 53 & $37.6 \%$ & $10.1 \%$ \\
$\quad$ Suppurative & 20 & $14.2 \%$ & $3.8 \%$ \\
bronchopneumonia & 5 & $3.5 \%$ & $1 \%$ \\
Haemorrhagic pneumonia & 3 & $2.1 \%$ & $0.6 \%$ \\
Pleurisy & 2 & $1.4 \%$ & $0.4 \%$ \\
Embolic pneumonia & 1 & $0.7 \%$ & $0.2 \%$ \\
Aspiration pneumonia & 141 & & $26.9 \%$ \\
Total & & & \\
\hline \hline
\end{tabular}

\section{B. The Pathological Observation of Pneumonia Included}

\section{1) Interstitial Pneumonia}

The results showed fifty-seven $(40.4 \%)$ of samples were diagnosed as interstitial pneumonia. Grossly, most parts of the affected lungs were enlarged due to the distribution of lesions that were often observed in dorsocaudal regions. Moreover, the affected lungs were pale, rubbery in texture, meaty in appearance and resisted the pressure. Additionally, both the occasional presence of rib impressions on the costal surfaces and the lack of visible exudates in airways were the essential gross signs of interstitial pneumonia (Fig. 1A). 
Histologically, there was a marked increase in lymphocytes, neutrophils, and macrophages infiltration in the interalveolar septas (not within the alveolar air spaces) beside the proliferation of smooth muscle and fibroblasts all resulting in thickening of the interalveolar septa (Fig. 1B).

In addition, hyperplasia of pneumocyte type II was noted in some cases (Fig. 1C). Moreover, some cases showed lymphoid hyperplasia with formation of prominent welldefined lymphoid nodules within the vicinity of adjacent bronchi (Fig. 1D).

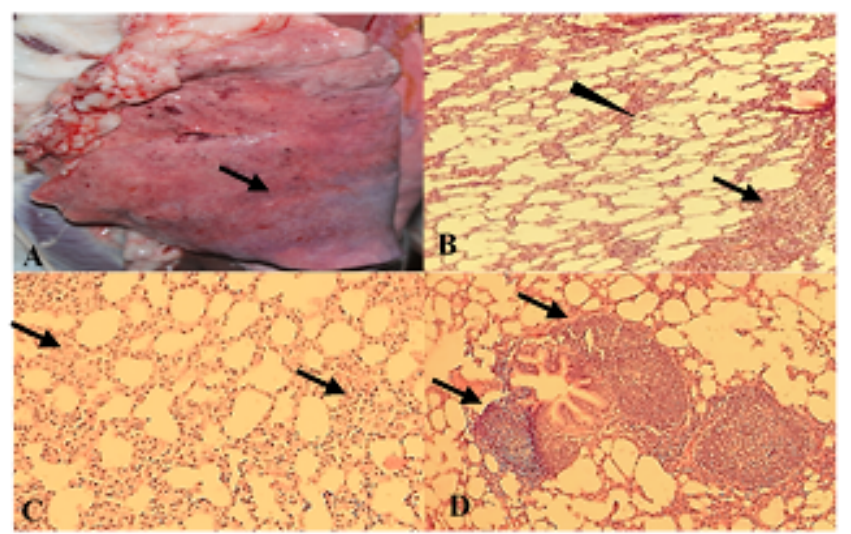

Fig. 1. A) Gross picture of interstitial pneumonia: Affected lung is pale, enlarged and rib impressions (black arrow) are observed. B) Microscopic picture of interstitial pneumonia: Interalveolar septa is thick (black arrowhead), the infiltration of inflammatory cells is interstitial (not within the alveolar air spaces) and consists almost exclusively of lymphocytes (black arrow) with no alveolar exudate. C) Hyperplasia of pneumocyte type II (black arrows). D) Peribronchial lymphoid hyperplasia with formation of prominent well-defined lymphoid nodules within the vicinity of adjacent bronchi (black arrows).

\section{2) Fibrinous Bronchopneumonia}

$37.6 \%$ of examined samples showed fibrinous bronchopneumonia. Grossly, the lesions were characterized by areas of consolidation with irregular shape and dark red in colour particularly in the cranial, cardiac, and accessory lobes (Fig. 2A). Moreover, the affected lungs were hard to cut due to pulmonary oedema, congestion and fibrin accumulation. A thin layer of fibrin usually covered the pleural surface of the affected areas (Fig. 2A). Histopathologically, the fibrinous bronchopneumonia was characterized by abundant capillary congestion, presence of multifocal areas of necrosis and variable amounts of fibrinous exudate in the lumen of the alveoli and bronchioles and these considered as the essential signs of this type of pneumonia (Fig. 2B \&C). Also, there was thickening in the interlobular septa and pleura because of oedema, inflammatory cells infiltration and fibrin accumulation (Fig. 2D). Some necrotic areas were surrounded by a rim of elongated cells, often referred to as 'oat cells, which were severely degenerated neutrophils mixed with alveolar macrophages (Fig. 2D).

\section{3) Suppurative Bronchopneumonia}

The results indicated $14.2 \%$ of samples were diagnosed as suppurative bronchopneumonia. Grossly, irregular dark red to grey-pink consolidation was noted particularly in the cranial, middle and accessory lobes (Fig. 3A). Moreover, the affected lungs appeared moist and purulent exudates leaked from bronchi and some absecesation of foci scattered throughout the affected part in the chronic phase (Fig. 3B).
Histopathologically, the suppurative areas were characterized by abundant polymorphonuclear cells (mainly neutrophils) infiltration in the lumen in the alveolar spaces, bronchi, and bronchioles in addition to macrophages, sloughed epithelial cells, necrotic debris and various amounts of mucus and fibrin were observed within the lumen of the bronchi, bronchioles, and alveoli (Fig. 3C). In the chronic phase, there was thickening of alveolar walls due to the infiltration of neutrophils, lymphocytes and macrophage. Also, there was hyperplasia of goblet cells of the bronchiolar epithelium that changed the exudates to mucopurulent and extensive accumulation of lymphocytes in peribronchial region in some cases (Fig. 3D).

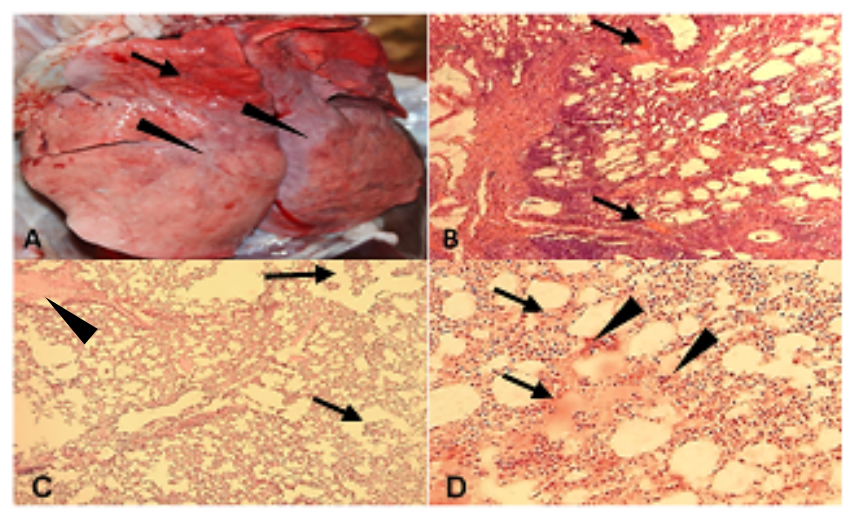

Fig. 2. A) Gross picture of fibrinous bronchopneumonia: Affected lung has areas of consolidation with irregular shape and dark colour (black arrow) and there is a thin layer of fibrin usually covered the pleural surface of the affected (black arrowheads). B) Microscopic picture of fibrinous bronchopneumonia: capillary congestion (black arrows), C) Multifocal areas of necrosis (black arrows) and variable amounts of fibrinous exudate presented in the lumen of the alveoli and bronchioles (black arrowhead).

D) Thickening in the interlobular septa because of oedema, inflammatory cells infiltration and fibrin accumulation (black arrows) and 'oat cells (black arrowheads).

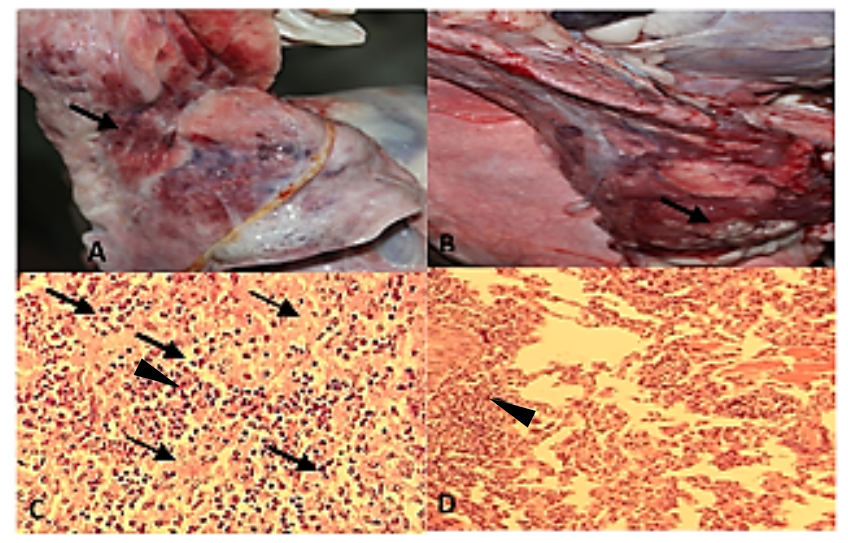

Fig. 3. A) Gross picture of suppurative bronchopneumonia: irregular dark red consolidation (black arrow). B) some absecesation of foci scattered throughout the affected part in the chronic phase (black arrow). C) Microscopic picture of suppurative bronchopneumonia: the suppurative areas were characterized by abundant polymorphonuclear cells (mainly neutrophils) infiltration (thick black arrows), macrophages, sloughed epithelial cells, necrotic debris (black arrowhead) and various amounts of mucus and fibrin were observed (thin black arrows). D) Thickening of alveolar walls, mucopurulent exudate and extensive accumulation of lymphocytes in peribronchial region in the chronic phase (black arrowhead).

\section{4) Haemorrhagic Pneumonia}

Haemorrhagic pneumonia was noticed in $3.5 \%$ of samples. Grossly, remarkably red area was seen in the affected lungs (Fig. 4A). 
Histopathologically, the presence of a large number of $\mathrm{RBC}$ was seen in alveoli and inter-alveolar septa, associated with leukocytic infiltration (Fig. 4B\&C). Also the presence of a large number of hemosiderophages out of the blood vessels were prominent (Fig. 4D).

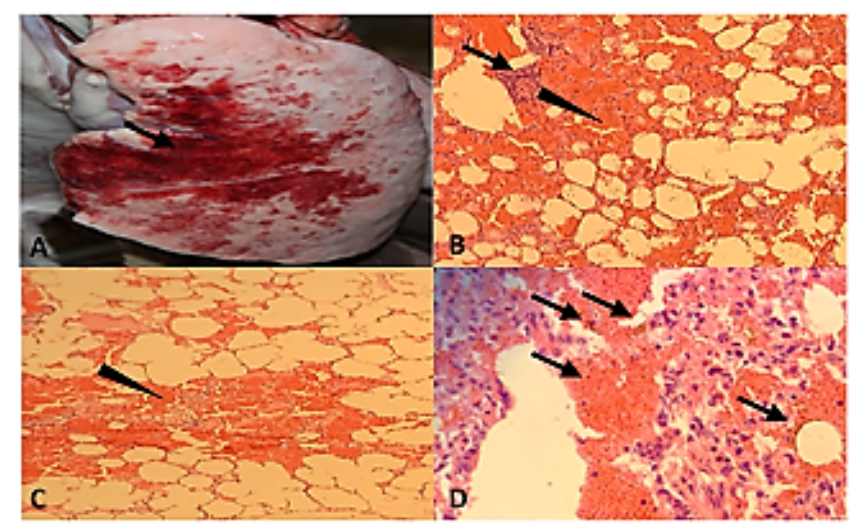

Fig. 4. A) Gross picture haemorrhagic pneumonia: the affected lungs displayed remarkably red area (black arrow). B \&C) Microscopic picture of haemorrhagic pneumonia: there was a large number of $\mathrm{RBC}$ was seen in alveoli and inter-alveolar septa (black arrowheads) as well as leukocytic infiltration (black arrow). D) The presence of of hemosiderophages out of the blood vessels were prominent (black arrows).

\section{5) Pleurisy}

The occurrence of pleurisy was $2.1 \%$ in this study. Grossly, pleurisy was characterized by thickness and cloudiness in pleura, fibrinous adhesions between the parietal pleura and the lung surface and sometimes with the internal thorax cavity (Fig 5A). Histopathologically, thickening of the pleura due to the formation of granulation tissue and fibrosis was observed (Fig 5B). In some cases fibrinous pleurisy with adhesion to the thorax was noted.

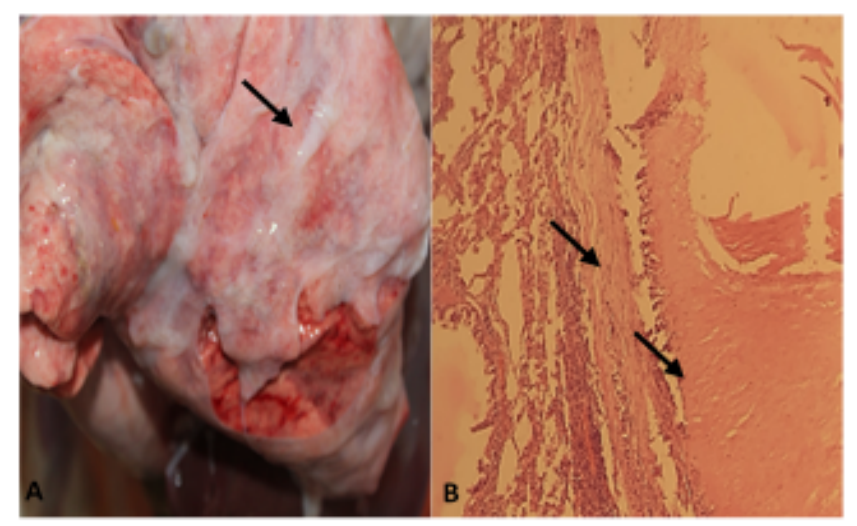

Fig. 5. A) Gross picture of pleurisy: there is thickness and cloudiness in pleura in the affected lungs (black arrow). B) Microscopic picture of pleurisy: thickening of the pleura due to the formation of granulation was seen (black arrows).

\section{6) Embolic Pneumonia}

$1.4 \%$ of the examined sheep showed. Grossly, white multifocal nodules sized 4-6 $\mathrm{mm}$ and surrounded by a discrete, red, haemorrhagic area were distributed randomly throughout the pulmonary lobes (Fig. 6A). Histopathologically, embolic pneumonia was characterised by multifocal neutrophilic aggregations scattered randomly throughout the pulmonary lobes (Fig. 6B).

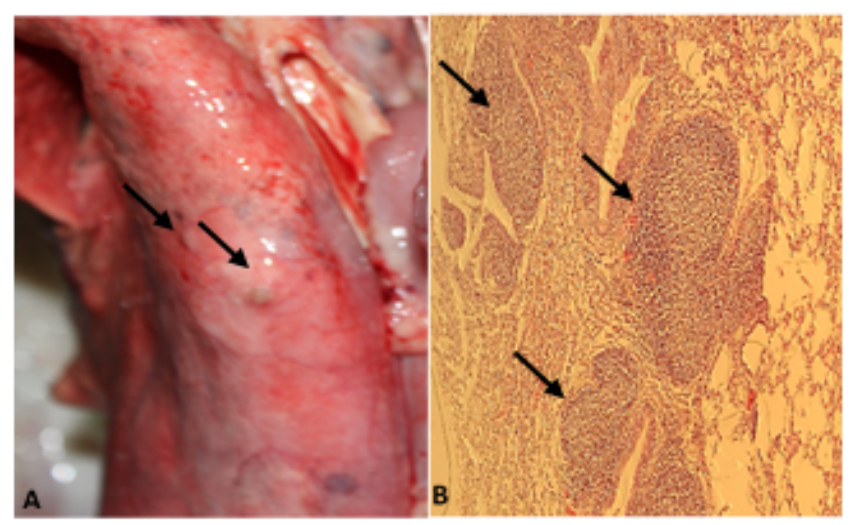

Fig. 6. A) Gross picture of embolic pneumonia: multifocal small in size white foci surrounded by a discrete, red, hemorrhagic area distributed randomly throughout the pulmonary lobes (black arrows). B) Microscopic picture of embolic pneumonia: multifocal neutrophilic aggregations scattered randomly throughout the pulmonary lobes (black arrows).

\section{7) Aspiration Pneumonia}

Aspiration pneumonia were detected in $0.7 \%$ of the samples. Grossly, dark brown, congested and somewhat meaty in consistency area was seen in the affected lungs (Fig. 7A). Histopathologically, the presence of aspirated foreign material in tissue (Fig. 7B).

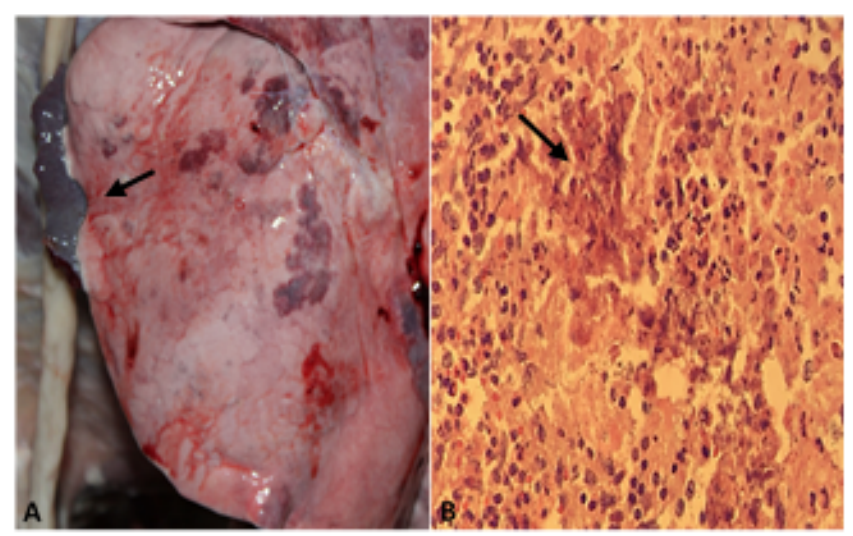

Fig. 7. A) Gross picture of aspiration pneumonia: the presence of dark brown, congested and somewhat meaty in consistency area in affected lung (black arrow). B) Microscopic picture of aspiration pneumonia: the presence of aspirated/foreign material in tissue (black arrow).

\section{DISCUSSION}

Respiratory diseases are common in various species of domestic animals particularly the herbivores leading to retarded growth and reduced weight-gains in recovered animals, slaughterhouse wastage, drugs and labour costs as well as high mortality rate. All these consequences cause a major economic impact on the sheep industry. Pneumonia in ruminants, as one of the most respiratory diseases, is a complex condition resulting from interaction between a number of factors including the host (i.e. immunological and physiological), multiple agents (e.g. bacterial, viral, mycoplasma, parasitical) and environmental factors [19].

The present study, to our knowledge, shows for the first time the frequency, types and nature of gross and microscopic lesion of pneumonia observed in sheep slaughtered at Libya. 
The present study shows that out of 525 sheep lungs examined, $141 \quad(26.9 \%)$ showed gross pneumonia. Pneumonia was classified into 7 subgroups according to their macroscopic and microscopic appearances. This result showed that pneumonia is one of the most important causes of sheep morbidity in Libya similarly other countries [3]-[10], [12], [17], [18], [20]-[26].

Interstitial pneumonia was encountered on $40.4 \%$ of the examined sheep lungs. The results of the present study are consistent with the [21] and the report of [23] who reported interstitial pneumonia in $41.9 \%$ and $23.6 \%$ of the samples respectively with the highest incidence. On the other hand, this finding is in disagreement with the report of [7], the report by [10], the study by [18], the report of [24] the study by [25] and the report of [27], who had observed interstitial pneumonia in $11.9 \%, 8 \%, 16 \%, 5 \%, 15 \%$ and $13.6 \%$ of the affected sheep respectively.

It was of interest that, in this and the study of [21], the interstitial pneumonia had a high prevalence and was conducted nearly in the same time of the year (from October to April for this study and from February to April for [21]), whereas the other studies were conducted from October to January [8], from February to November the following year [24] and from December to February [27]. Therefore, further work is required to examine the incidence of interstitial pneumonia during rest of the year.

The present study has also demonstrated that fibrinous bronchopneumonia was found to be the second most prevalent pathological finding with $37.6 \%$ occurrence in agreement with the report of [27] who reported fibrinous bronchopneumonia in Iraq was the second most prevalent pathological finding with $27.8 \%$. Also, the report by [21] showed high incidence of fibrinous bronchopneumonia $24.3 \%$. Unlike the results of the present study, [7] recorded a prevalence of $7.14 \%$, the report of [8] recorded a prevalence of $15 \%$, the study by [18] recorded a prevalence of $3.94 \%$ and the report by [24] showed an incidence of $7.5 \%$.

Suppurative bronchopneumonia was found in $14.2 \%$ of the examined cases. Studies conducted by [7] in Southern Iran, [21] in Ethiopia, [8] in Duhok in Iraq and [10] in Western Iran indicated a prevalence of $45 \%, 25.7 \%, 20 \%$ and $32.5 \%$ suppurative bronchopneumonia respectively. The highest incidence was seen in Baghdad in Iraq with 58.6\% [27] whereas the lowest incidences of Suppurative bronchopneumonia recorded in Bangladesh with 5\% [25], in Colombia with 3\% [20] and in Egypt with 6.7\% [24].

Based on the literature the incidence of haemorrhagic pneumonia is low. In this study haemorrhagic pneumonia was detected in $3.5 \%$ of examined lungs. Similar findings were reported in anther studies conducted in Bangladesh with 3.3\% [25].

The Pleurisy was observed in $2.1 \%$ of the examined lungs similar to reported by [7] $(2.33 \%)$, to reported by [10] $(4.06 \%)$ and to reported by [24] (4.5\%). However, these rates are much lower than that reported by [12], [20] who observed presence of a pleurisy in $34 \%$ and $68 \%$ of examined samples respectively.

Embolic pneumonia was found in $1.4 \%$ of the cases. This is in agreement with the study from Southern Iran 2.38\% [7]. This value, however, is much lower than that reported by [20] who has reported a prevalence of $13 \%$ in samples.
The present study has also demonstrated that the occurrence of aspiration pneumonia in this study was $0.7 \%$ when compared with the literatures the rate of aspiration pneumonia was higher in Ethiopia (4.7\%) [21].

Concerning macroscopical and microscopical pictures, the gross and histological lesions of the different forms pneumonia were consistent with the findings of other studies. Similarly to large number of studies [3]-[10], [12], [17] [18], [20]-[26], the majority (51.8\%) of bronchopneumonia noted in the current study was chronic type and these types could be associated with contagious pneumonic pasteurellosis as these diseases are characterized by fibrinous and suppurative bronchopneumonia patterns. Therefore, further work is required to examine the causes of these types of pneumonia.

Several factors may play roles in the high prevalence of pneumonia in this region. These factors include moving lambs from poor pasture (grass from April to mid-May, and on the remnants of the harvest of wheat and barley fields from mid-May to the end of June) to richer aftermath pasture in summer (imported fodder, especially barley). Also, extreme weather conditions or changes, concurrent infections involving other respiratory pathogens, stress due to handling, poor housing and overcrowding may take part in the high prevalence of pneumonia in this region. On the other hand, this variation in prevalence of pneumonia types between this study and some other studies probably could be ascribed to countries geography, environmental conditions and time of study conducted.

This suggests that the disease was most likely attributed to exposure of the animals to various stresses like overcrowding, sudden climate change and inadequate feed and water provision, and other underling diseases including predisposing viral infection of the respiratory system such as parainfluenza- 3, adenoviruses, and respiratory syncytial virus are widely accepted as predisposing factors for bacterial pneumonia [21], [28].

\section{CONClusion}

In conclusion, the results of this study indicates that the prevalence of pneumonia in slaughtered sheep is relatively high in Libya and seems to be the most important condition in sheep. Macroscopical and microscopical pictures of this study gives a hint about the causes and the types of pneumonia as this study unveiled that $27 \%$ of sheep slaughtered at Libya were affected with different forms of pneumonia. Interstitial and fibrinous pneumonia were the major forms of detected pneumonia.

The high prevalence of these lesions effect the quality of the meat and increase in slaughtered wastage in addition to a lot of economic loss in the animal husbandry industry. Additionally, this histopathological study provides a clue to the nature and type for prompt treatment in any outbreak. Therefore, histopathology examination for should be employed routinely as an ancillary test to generate additional epidemiological data for a better disease control and prevention measures. Further study is focused on the agent involved and responsible for the development of different these types of pneumonia. Also, additional work is required to examine the incidence of the types of pneumonia in sheep during rest of the year. 


\section{ACKNOWLEDGMENT}

The Authors gratefully acknowledge the Department of Animal Production at the Ministry of Agriculture and Livestock, EL-Beida - Libya, especially Mrs. Fathi Al-Kalili (Agronomist) and Alaa Al-Din MA Mohammed (Agronomist) for providing us with information about the number of animals and sheep in municipality of El-Beida and in Libya. The Authors also extend our gratitude to the staff members of Atellal abattoir for their cooperation during data collection. Special thanks also go to Mrs Monier MA Mohammed (mechanical engineer) and Ahmed AM Kalifa for their assistance in samples collection and the photographing.

\section{CONFLICT OF INTEREST}

Authors declare that they do not have any conflict of interest.

\section{REFERENCES}

[1] Brumby P. System and Livestock Dev't in Tropical Africa. Animal Disease as a Factor Limiting Economic Dev't in Africa. Cornell, Vet, . 1990;80:17-25.

[2] FAOSTA. [Internet] 2017. Available from: http://www.ipcinfo.org.

[3] Lacasta D, Ferrer LM, Ramos JJ, González JM, De las Heras M. Influence of climatic factors on the development of pneumonia in lambs. Small Rumin Res. 2008; 80(1-3): 28-32.

[4] Goodwin K, Jackson R, Brown C, Davies P, Morris R, Perkins N. Pneumonic lesions in lambs in New Zealand: patterns of prevalence and effects on production. $N Z$ Vet J. 2004; 52(4): 175-179.

[5] Habashy H, Fadel G, El Shorbagy G. Bacteriological and Pathological Studies on the Causes of Mortalities among Sheep in SharkiaGovernorate Farms. EGYPTAIN J Comp Pathol Clin Pathol. 1967; 22(1).

[6] Mohamed R, Abdelsalam EB. A Review on Pneumonic Pasteurellosis (Respiratory Mannheimiosis) With Emphasis on Pathogenesis, Virulence Mechanisms and Predisposing Factors. Bulg $\mathrm{J}$ Vet Med. 2008; 11(3): 139-160.

[7] Azizi S, Korani FS, Oryan A. Pneumonia in slaughtered sheep in south-western Iran: Pathological characteristics and aerobic bacterial aetiology. Vet Ital. 2013; 49(1): 109-10918.

[8] Mahdi AA, Al-Naqshabendy AA, Haddel BT. A study of some pathological lesions in the lung of sheep and Duhok abattoir. Basrah $J$ Vet Res. 2015; 14(2): 265-277.

[9] Abdelsalam EB, Al Sadrani AA. Incidental findings of pathological significance in pneumonic lungs of sheep in Al Qassim Area, Kingdom of Saudi Arabia: an abattoir survey. Comp Clin Path. 2015; 24(4): 951-955.

[10] Hashemnia M, Chalechale A, Malmir E. Pulmonary lesions in slaughtered sheep in western iran: Gross and histopathological findings. Vet Ital. 2019; 55(1): 47-56.

[11] Kumar M, Kumar R, Varshney K, Nair M, Lakkawar A, Palanivelu M. Pathomorphological studies of lung lesions in sheep. Indian J Vet Pathol. 2014; 38(2): 75.

[12] Lindström L, Tauni FA, Vargmar K. Bronchopneumonia in Swedish lambs: A study of pathological changes and bacteriological agents. Acta Vet Scand. 2018;60(1):1-8. doi:10.1186/s13028-018-0409-1

[13] Ali O, Abdelsalam E. Sheep pulmonary adenomatosis (Jaagsiekte) in Libya : gross and histopathological evidence. Rev d'élevage médecine vétérinaire des pays Trop. 1999;52(3-4):181-183. doi:10.19182/remvt.9660

[14] Ministry of Agriculture. [Internet] 2019. Avaiable from: Minist Agric Livest Mar Resour - Livest Prod Dep - Census 2019.

[15] Luna L. Manual of HISTOLOGIC STAINING METHODS of the Armed Forces Institute of Pathology. Mc Graw Hill, NewYork, NY, USA, 7th Ed 1968.

[16] Bancroft TD, Stevens A, Turner DR. Turner Theory and Practice of Histological Technique. 4th ed. Churchill, Livingstone; 1996.
[17] Singh R, Kumar P, Sahoo M, Bind R, Kumar K, Asok Das T, et al. Spontaneously occurring lung lesions in sheep and goats. Indian J Vet Pathol. 2017; 41(1): 18-24.

[18] Mishra S, Kumar P, George N, Singh R, Singh V, Singh R. Survey of lung affections in sheep and goats: a slaughterhouse study. J Entomol Zool Stud. 2018; 6(4): 118-120.

[19] Brogden KA, Lehmkuhl HD, Cutlip RC. Pasteurella haemolytica complicated respiratory infections in sheep and goats. Vet Res. 1998; 29(3-4): 233-254.

[20] Caicedo-Martínez JA, Ávila-Rubiano MA, Orellano-Badillo H, Sanjuanelo-Corredor DW. Patología pulmonar en ovinos faenados del norte del departamento de Bolívar, Colombia. Corpoica Cienc y Tecnol Agropecu. 2017; 18(3): 555-569.

[21] Mekibib B, Mikir T, Fekadu A, Abebe R. Prevalence of Pneumonia in Sheep and Goats Slaughtered at Elfora Bishoftu Export Abattoir, Ethiopia: A Pathological Investigation. 2019; 2019.

[22] Emikpe BO, Jarikre TO, Eyarefe OD. Retrospective study of disease incidence and type of pneumonia in Nigerian small ruminants in Ibadan, Nigeria. African J Biomed Res. 2013; 16(2): 107-113.

[23] Yesuf M, Mazengia H, Chanie M. Histopathologicaland Bacteriological Examination of Pneumonic Lungs of Small Ruminants Slaughtered at Gondar, Ethiopia. Am J Sci Res. 2012; 7(6): 226-231.

[24] El-Mashad AB, Moustafa S, Amin A, Samy E. Pathological Studies on lung affections in sheep and goat at Kalubia Governorate. Benha Vet Med J. 2020; 38(1): 17-23.

[25] Ferdausi T, Haider M, Alam KJ, Baki, MAHossain MM. Caprine lung diseases and causal bacteria. 2008; 25(1): 9-16.

[26] Ferdausi T, Haider M, Alam K, Baki M, Hossain M. Caprine lung diseases and causal bacteria. Bangladesh Vet. 1970; 25(1): 9-16.

[27] Mahamud MD, Zenad K. A study of some pathological lesions in the lung of sheep at khanakin abattoir. Int J Adv Biol Res. 2017; 7(2): 378381.

[28] Alhaji UN, Rivera J, Atapattu DN, Owusu-ofori K, Czuprynski CJ. Gene expression profiling of bovine bronchial epithelial cells exposed in vitro to bovine herpesvirus 1 and Mannheimia haemolytica haemolytica. 2020. 